\title{
THE UTILITY OF UPPER DIGESTIVE ENDOSCOPY IN THE EVALUATION OF HIV PATIENTS WITH LOW CD4+ T-LYMPHOCYTE VALUES
}

\author{
Mihaela C. OLARIU ${ }^{1}$, Iulia VASILESCU ${ }^{2}$, Adriana NURCIU ${ }^{2}$, Ecaterina C. BARBU ${ }^{1}$, \\ Cristina E. CHITU ${ }^{1}$, Mihaela A. IANCU ${ }^{1}$, Oana SANDULESCU ${ }^{1}$, Anca STREINU-CERCEL', \\ Mihai H. OLARIU², Camelia C. DIACONU ${ }^{1,3 凶}$
}

${ }^{1}$ „Carol Davila“ University of Medicine and Pharmacy, Bucharest, Romania

${ }^{2}$ National Institute of Infectious Diseases „Matei Bals“, Bucharest, Romania

${ }^{3}$ Clinical Emergency Hospital of Bucharest, Romania

Received 12 July 2019, Accepted 21 Sept 2019

https://doi.org/10.31688/ABMU.2019.54.4.01

\section{Abstract}

Introduction. The digestive tract is invariably affected in HIV-infected patients and should be investigated especially in patients with longer disease duration. The significance of decreasing CD4+ cell counts as a predictive factor for the existence and severity of upper gastrointestinal lesions has been previously evaluated in some studies, that demonstrated a link between this parameter and the frequency or extent of esophageal or gastric lesions.

The objective of the study was to investigate the upper digestive tract infections in HIV-infected patients and to establish the link between endoscopic changes (type and location) and the peripheral CD4+ cell counts.

Material and methods. This is a retrospective cohort study. 88 HIV-infected patients, hospitalized for clinical and biological evaluation between November 2015 and July 2018 in the National Institute for Infectious Diseases „Prof. Dr. Matei Bals“, Bucharest, Romania,

\section{Résumé}

L'utilité de l'endoscopie digestive haute dans l'évaluation des patients avec VIH aux valeurs basses de lymphocytes T CD4+

Introduction. Le tube digestif est invariablement affecté chez les patients infectés par le VIH et doit être étudié en particulier chez les patients présentant une maladie de plus longue durée. L'importance de la diminution du nombre de cellules CD4 + en tant que facteur prédictif de l'existence et de la gravité des lésions du tractus gastro-intestinal supérieur a déjà été évaluée dans le cadre de certaines études démontrant qu'il existe un lien entre ce paramètre et la fréquence ou l'étendue des lésions œesophagiennes ou gastriques. L'objectif de l'étude était d'étudier les infections du tractus digestif supérieur chez les patients infectés par le VIH et d'établir le lien entre les modifications endoscopiques (type et localisation) et le nombre de cellules CD4 + périphériques. 
were investigated by upper digestive endoscopy. In all patients, CD4+ T-lymphocyte values were determined. Results. Our study emphasizes a greater probability of developing lesions of the upper digestive tract and a greater frequency of esophagitis in HIV-infected patients with low CD4+ T-lymphocyte values compared to patients with normal values. The most commonly involved segment is the esophagus. The most common gastric lesion is gastritis, which in patients with lymphocytic depletion affects the entire gastric mucosa.

Conclusions. The results of the study support the necessity of routine evaluation by upper digestive endoscopy of HIV-infected patients with low CD4+ T-lymphocyte values, irrespective of the presence or absence of symptoms specific for upper digestive tract lesions, both for diagnostic and epidemiological purposes.

Keywords: HIV, digestive lesions, endoscopy, CD4+ T-lymphocyte.

\begin{abstract}
Abbreviations:
HIV - Human Immunodeficiency Virus; SHIVSimian/Human Immunodeficiency Virus; HAART Highly Active Antiretroviral Therapy; IDO - indoleamine 2,3-dioxygenase; CMV - Cytomegalovirus; HSV - Human Simplex Virus; HHV - Human Herpes Virus; GERD - Gastroesophageal Reflux Disease; PHG - Portal Hypertensive Gastropathy; EV - esophageal varices.
\end{abstract}

\section{INTRODUCTION}

\section{HIV infection - Current epidemiological context}

Over the last two decades, the epidemiology of HIV infection has changed. The increased efficacy of antiretroviral drugs in HIV infection is viewed as an essential factor in the drop of HIV-related mortality rate, from a maximum of 1,900,000 in 2005 to $1,000,000$ in $2016^{1}$. The worldwide prevalence of HIV infection has increased, since effective therapy increases the life expectancy of infected people, while the incidence of infection has decreased, largely due to a decrease in heterosexual transmission and the implementation of intensive programs addresssing risk behaviors of intravenous drug users ${ }^{2}$.

\section{The number of CD4+ T lymphocytes - a valu- able biological marker for immunosuppression in HIV-infected patients}

The depletion of CD4+ lymphocytes plays an important role in the pathophysiology of HIV infection in the human body. The main role of the CD4+' decrease in the pathogenic mechanisms of HIV infection was demonstrated by experimental infections
Méthodes. C'est une étude rétrospective de groupe. 88 patients infectés par le VIH, hospitalisés pour évaluation clinique et biologique entre novembre 2015 et juillet 2018 à l'Institut national des maladies infectieuses «Prof. Dr. Matei Bals ", Bucarest, Roumanie, ont été étudiés par endoscopie digestive haute. Chez tous les patients, les valeurs des lymphocytes T CD4 + ont été déterminées.

Résultats. Notre étude met en évidence une plus grande probabilité de développer des lésions du tube digestif supérieur et une plus grande fréquence d'œsophagite chez les patients infectés par le VIH présentant des valeurs faibles de lymphocytes T CD4 + par rapport aux patients ayant des valeurs normales. Le segment le plus fréquemment impliqué est l'œsophage. La lésion gastrique la plus courante est la gastrite qui, chez les patients présentant une déplétion lymphocytaire, affecte l'entière muqueuse gastrique.

Conclusions. Les résultats de l'étude confirment la nécessité d'une évaluation systématique par endoscopie digestive haute des patients infectés par le VIH présentant de faibles valeurs de lymphocytes T CD4 +, indépendamment de la présence ou de l'absence de symptômes spécifiques aux lésions du tube digestif supérieur, à des fins diagnostiques et épidémiologiques.

Mots-clés: VIH, lésions digestives, endoscopie, lymphocytes T CD4.

with chimeric SHIV virus in primates, in whom an AIDS-like syndrome was successfully reproduced, with the rapid death of the infected animals by the complete depletion of $\mathrm{CD} 4+\mathrm{T}$ cells $\mathrm{s}^{3,4}$.

The infectious viral strains require the presence of the CCR 5 co-receptor on the surface of the target cell, preferentially attacking the CD4+ T lymphocytes with memory, differentiated cell subset in the extra-lymphoid effector sites, e.g. the ones in the digestive mucosa that are first destroyed during the acute phase of the infection, long before the installation of AIDS 5 .

The objective of the Study was to establish the necessity of routine evaluation by upper digestive endoscopy of HIV-infected patients with low CD4+ T-lymphocyte values, irrespective of the presence or absence of suggestive digestive symptomatology.

\section{Materials AND MEthods}

This was a retrospective cohort study. 88 HIVinfected patients, hospitalized for clinical and biological evaluation between November 2015 and July 
2018 in the National Institute for Infectious Diseases „Prof. Dr. Matei Bals“, Bucharest, Romania, were investigated by upper digestive endoscopy. In all patients, CD4+ T-lymphocyte values were determined. All the patients signed an informed consent. The study was approved by the Ethics Committee of the National Institute for Infectious Diseases „Prof. Dr. Matei Bals", Bucharest, Romania.

The patients were divided into two groups, based on their CD4+ T-lymphocyte values: a control group - 34 patients with CD4+ with normal values (410-1590 cells $\left./ \mathrm{mm}^{3}\right)$ and a study group - 54 patients with low CD4+ values. Comparative analyses were performed on the lesions detected endoscopically in the esophagus, stomach, and duodenum, in order to highlight a possible relationship between immunological depression (reflected by CD4+ depletion) and the characteristics of the digestive lesions.

For statistical interpretation of the results, we used contingency tables and the CHITEST Excel function. A p-value $<0.05$ is associated with statistical significance of the results obtained.

\section{Results}

88 patients with serologically proven HIV infection were investigated by upper digestive endoscopy. In all patients, biological tests results $(\mathrm{CD} 4+$ cell counts) were available for a period of $+/-3$ months before and after endoscopy.

35 out of the 54 patients (64.8\%) from the study group had severe CD4+ depletion $(<200$ cells $/ \mu \mathrm{L})$.

\section{The distribution and spectrum of esophageal, gastric and duodenal lesions in the analyzed groups}

The average age of the patients from the group of study was 36.5 years, and the gender distribution was male/women $1.5 / 1$ (60.3\% men and $39.7 \%$ women).

Of the total of 88 patients, in 28 cases (31.8\%) no pathological changes at the upper digestive endoscopy were noticed. A higher proportion of endoscopic abnormalities were seen in patients with low CD4+ cell counts ( $76 \%$ presented endoscopic abnormalities) compared to patients without lymphocyte depletion (55.88\% presented endoscopic abnormalities), equivalent to a relative risk $R R=1.35$. The distribution of the endoscopic lesions of the digestive segments in the two study groups is shown in Fig. 1 and Fig. 2.

A higher frequency of esophageal lesions compared to gastric lesions in patients with lymphocyte depletion $(9.25 \%$ vs $23.53 \%)$ was observed. In both groups, the duodenal lesions were rare and, when present, they accompanied the lesions of the proximal segments. The lymphocyte depletion is a risk factor for pathological changes in the esophagus and stomach, with a calculated relative risk $\mathrm{RR}=2.16, \mathrm{p}=$ 0.004, CI 95\%.

Strictly considering the esophageal lesions, a higher risk was observed in patients with low CD4-cell counts compared to the ones with normal values, $R R=1.77$ ( $p=0.02$, CI 95\%), the result being statistically significant.

The most common type of esophageal lesion was esophagitis, present in $29.4 \%$ of the patients with normal CD4+ cell counts and in $64.7 \%$ of those

The distribution of the endoscopic lesions in patients with low CD4+ cell counts (PHT - portal hypertension, EV - esophageal varices, PHV - portal hypertensive gastropathy)

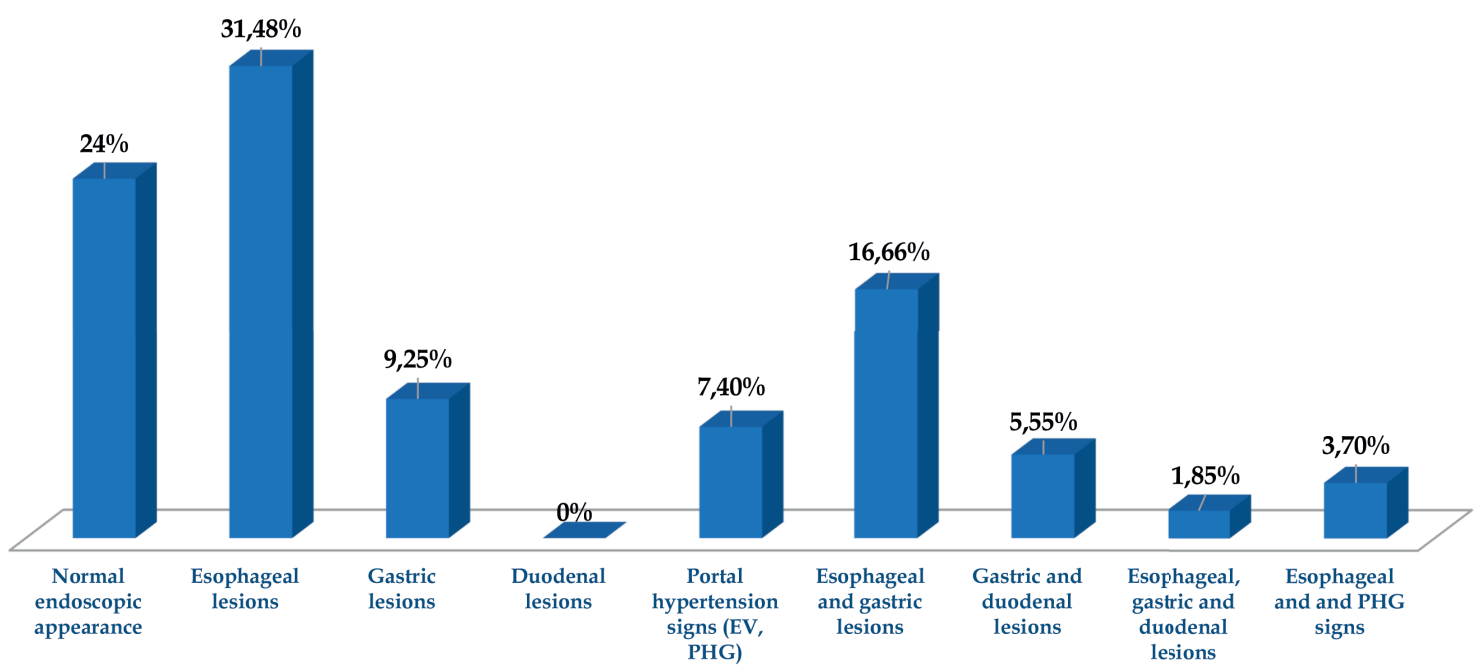

Fig. 1. The distribution of the endoscopic digestive lesions in patients with low CD4+ cell counts. 


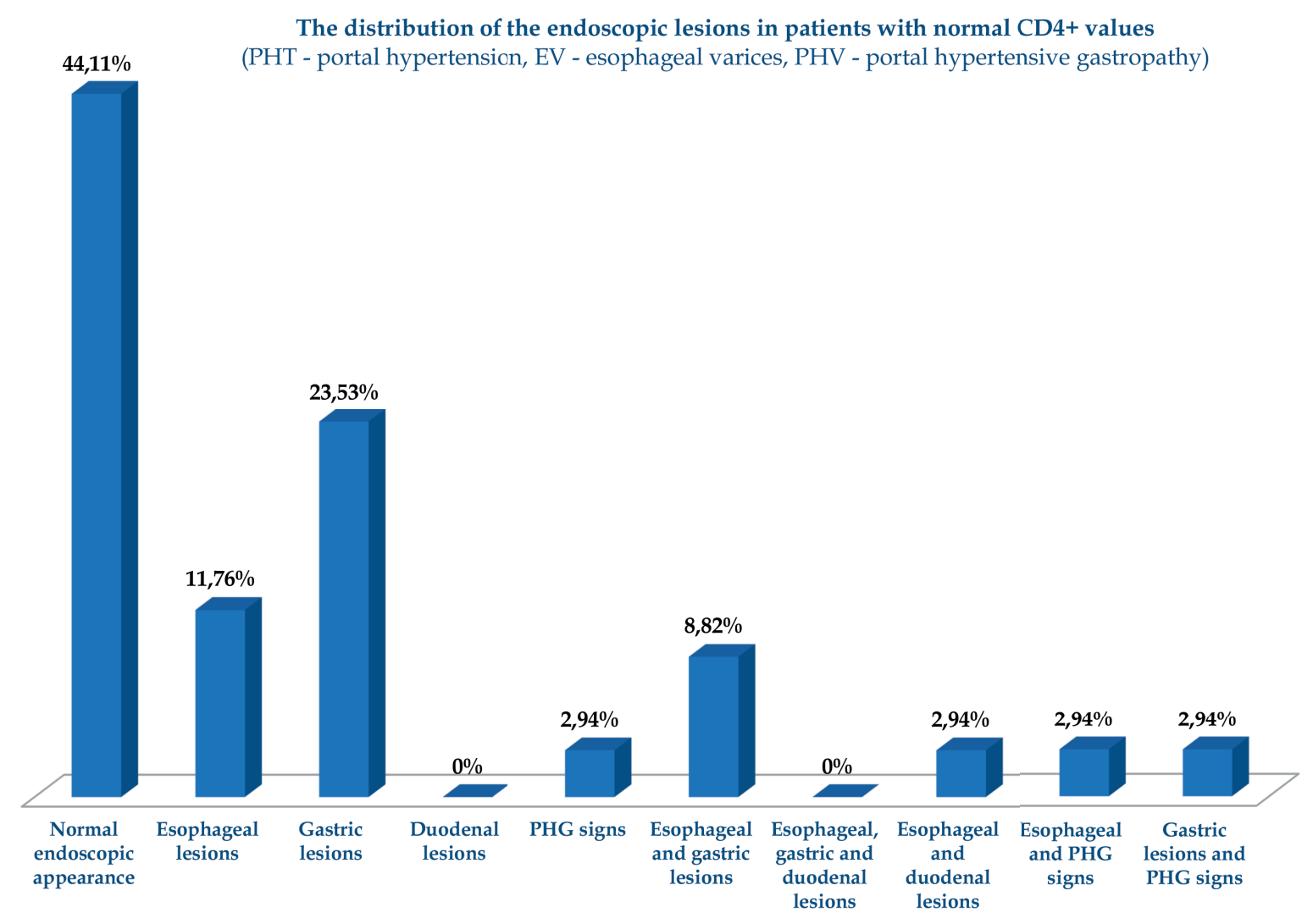

Fig. 2. The distribution of the endoscopic digestive lesions in patients with normal CD4+ cell counts.

with low CD4+ cell counts, equivalent to a relative risk $\mathrm{RR}=1.38$ for the patients with lymphocytic depletion to develop esophagitis versus those with normal peripheral CD4+ cell counts ( $\mathrm{p}=0.28$, CI 95\%). Esophageal ulcers were found only in the group of patients with low CD4+ cell counts (20.58\% of patients, $\mathrm{p}=0.02$ ), most frequently being multiple.

The considerations on the etiology of esophagitis can only be speculative, the specific tests for the identification of infectious causes being currently not systematized for technical reasons. Of ten biopsies harvested from esophageal ulcerations in patients with low CD4+ cell counts, microscopic lesions characteristic for herpetic etiology could be found in only two cases, in the rest of the cases the changes were non-specific.

Gastric lesions were less common than esophageal lesions, regardless of the number of $\mathrm{CD} 4+$ peripheral cells. More than half of the patients didn't present gastric or duodenal alterations. When present, the gastric lesions come most frequently as pangastritis in patients with lymphocyte depletion (20.58\%) and more rarely as antral gastritis. In the group of patients with normal CD4+ cell counts, there was no preferential localization of the inflammation, gastritis limited to the antral region being equally common as pangastritis. Although the relative risk of gastric and/or duodenal lesions was greater in patients with lymphocyte depletion ( $\mathrm{RR}=2.54$, CI $95 \%$ ), the result had no statistical significance $(\mathrm{p}=0.97)$.

Antral gastritis or pangastritis, associated or not with duodenitis, is the most common pathology observed during endoscopic examination $-26.13 \%$ of the patients with lymphocyte depletion and $29.4 \%$ of those with normal CD4+ cell counts (Fig. 3,4). HIV-infected patients with lymphocyte depletion present a higher risk of gastritis than those with normal CD4+ cell counts $(R R=0.75, p=0.44$, CI 95\%). The frequency of gastric and duodenal ulcerative lesions was low in the analyzed groups $-5.88 \%$ of the patients with normal CD4+ cell counts, and $8.49 \%$ of the patients with lymphocyte depletion. The relative risk of gastric or duodenal ulcer is slightly higher in patients with normal CD4+ cell counts, but has no statistical significance $(\mathrm{RR}=1,25, \mathrm{p}=0,78$, CI 95\%) (Table 1).

Regarding the infection with Helicobacter pylori, out of the 14 histopathological results available for the patients from the group of study, $50 \%$ were positive for $\mathrm{H}$. pylori and $50 \%$ negative, the data were insufficient to formulate a correct conclusion on the infection incidence in HIV-infected patients with lymphocyte depletion. 
The spectrum of gastric and duodenal lesions in patients with low CD4+ cell counts ( $\mathrm{G}=$ gastric, $\mathrm{D}=$ duodenal, $\mathrm{PHV}$ - portal hypertensive gastropathy)

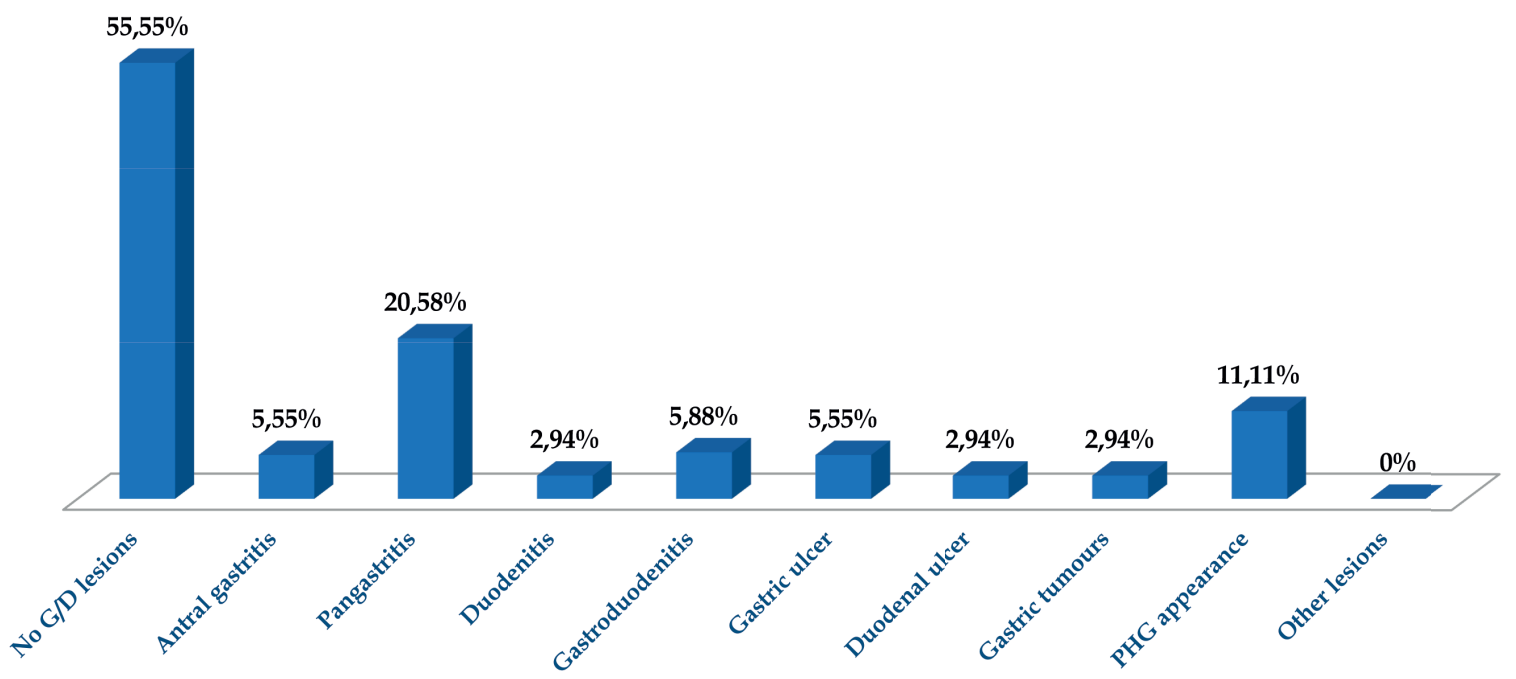

Fig. 3. The distribution of gastro-duodenal lesions in patients with low CD4+ cell counts.

The spectrum of gastric and duodenal lesions in patients with normal CD4+ values ( $\mathrm{G}=$ gastric, $\mathrm{D}=$ duodenal, $\mathrm{PHV}$ - portal hypertensive gastropathy)

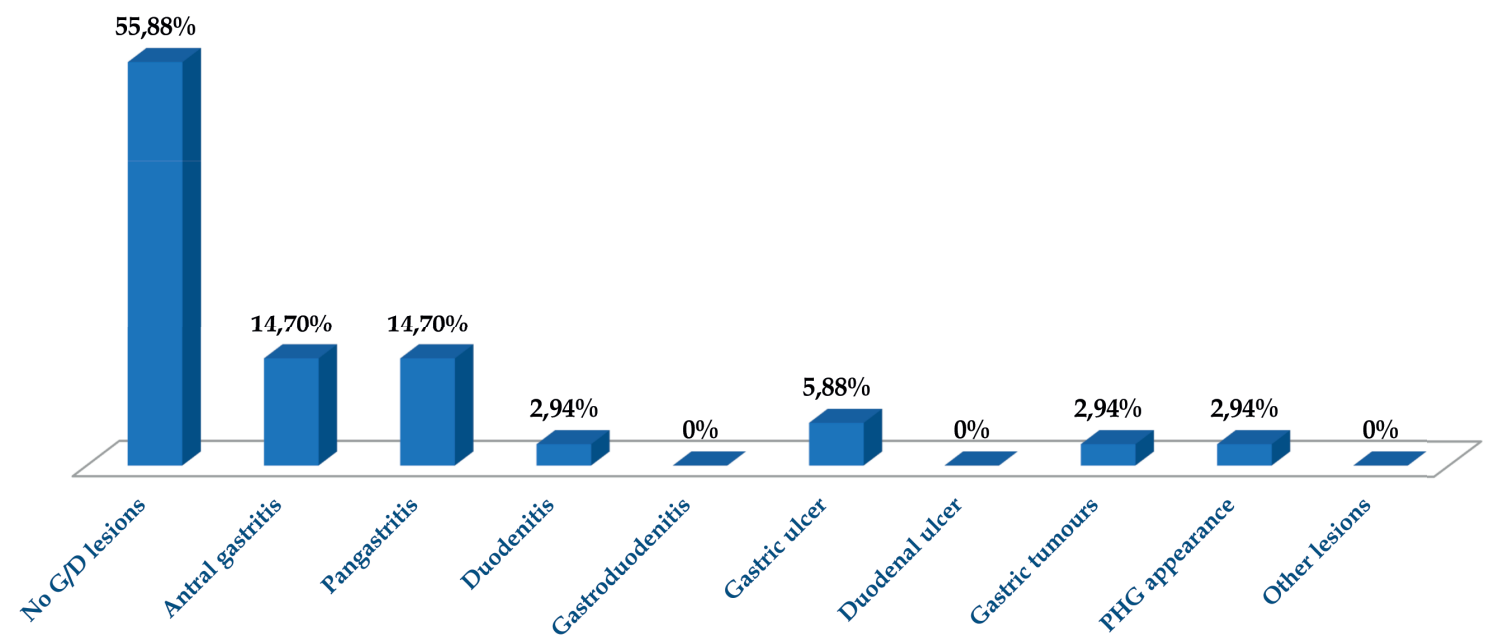

Fig. 4. The distribution of gastro-duodenal lesions in patients with normal CD4+ cell counts.

Portal hypertension signs (esophageal varices, hypertensive portal gastropathy) were found in $3 \mathrm{pa}-$ tients from the control group and 6 patients from the study group, a relatively small number of cases, given that approx. $41 \%$ of all the patients had positive serological markers for hepatitis infections $-25 \mathrm{pa}-$ tients from the study group (14 - HCV, 6 - HBV, 5 $\mathrm{HBV}+\mathrm{HDV}$ ) and 11 patients from the control group (5 - HCV, 4 - HBV, 2 - HBV+HDV).

The lymphocyte depletion was not linked to a high risk of chronic viral hepatitis ( $R R=0.43$, CI 95\%, $\mathrm{p}=0.057)$. Also, after calculating the risk of progression of liver disease in these patients (the emergence of portal hypertension), we found that patients with lymphocyte depletion do not present a greater risk than the ones with normal CD4+ cell counts $(\mathrm{RR}=0.88$, CI 95\%, $\mathrm{p}=0.83)$.

\section{Discussion}

\section{The pathogenesis of gastrointestinal damage in HIV-infected patients}

The gastrointestinal tract is invariably affected by HIV infection. In half of the cases, the digestive lesions are symptomatic and almost all HIV-infected patients will experience gastrointestinal complications 
Table 1. The correlation between the main lesions of the upper digestive tract and the immunological status in HIV-infected patients.

\begin{tabular}{ccc}
\hline Type of lesion & $\begin{array}{c}\text { Relative risk calculated for patients } \\
\text { with low CD4+ cell counts }\left(<410 / \mathrm{mm}^{3}\right)\end{array}$ & $\begin{array}{c}\text { Statistical significance } \\
(\text { CI } 95 \%)\end{array}$ \\
\hline Any type of lesion & 2.16 & $\mathrm{p}=0.004$ \\
\hline Esophagitis & 1.38 & $\mathrm{p}=0.028$ \\
\hline Gastric/duodenal lesions & 2.54 & $\mathrm{p}=0.97$ \\
\hline Gastritis with or without duodenitis & 0.75 & $\mathrm{p}=0.44$ \\
\hline Gastric/duodenal ulcer & 1.25 & $\mathrm{p}=0.78$ \\
\hline $\begin{array}{c}\text { Portal hypertension signs in patients with } \\
\text { chronic viral infection }\end{array}$ & 0.88 & $\mathrm{p}=0.83$ \\
\hline
\end{tabular}

during the course of the disease $\mathrm{e}^{6-8}$. The symptoms (anorexia, weight loss, dysphagia, odynophagia, diarrheal syndromes, abdominal pain) are non-specific or multi-factorial. It is now accepted that both HIV-1 in humans and SIV in primates are linked to the destruction of most gastrointestinal tract CD4+ $\mathrm{T}$ cells, starting from the very first weeks of infection, massive depletion which is not reflected in the circulating lymphocytes count. The CD4+ cells destroyed at mucosal level cannot be entirely replaced, so the host remains with a CD4+ memory deficiency?.

Most CD4+ T-lymphocytes are found in the intestinal tract, lymph nodes and other lymphoid structures of the body and much less in peripheral blood $^{10}$. A great number of the CD4+ T cells which are functionally attached to the digestive system present the CCR 5 co-receptor which is necessary for HIV intracellular penetration ${ }^{11}$.

The disruption of the epithelial barrier leads to the exposure of the underlying tissues to a multitude of antigens in the intestinal lumen, some of them with pro-inflammatory potential. As the disease progresses, bacterial translocation and inflammatory process are spreading and generalizing, with moderate effects due to the prompt initiation of antiretroviral therapy ${ }^{12,13}$. Indirect evidence of intestinal epithelial barrier disruption, bacterial translocation and inflammatory processes comes from studies which demonstrated an increased plasma concentration of substances associated with these processes, such as lipopolysaccharide (LPS), CD14s (LPS co-receptor), intestinal fatty-acid binding protein (I-FABP) (biomarker of apoptosis in intestinal epithelial cells) and the decrease of others, such as zonulin ${ }^{14}$.

Out of the various population of CD4+ cells, the ones produced by IL-17 and IL-22 are involved in both antimicrobial and immunological mechanisms and in maintaining the integrity of the intestinal barrier ${ }^{15,16}$. Th17 cell differentiation is inhibited through up-regulation of tryptophan metabolism by indoleamine 2,3-dioxygenase (IDO) enzyme induction by interferon and bacterial products. The latter, including LPS, stimulate dendritic cells, which locally produce IFN- $\alpha$ and activate IDO-dependent pathways, leading to the differentiation of $\mathrm{T}$ cells in the regulatory phenotype and not in the Th17 phenotype, with the decrease of this cell subset, thereby accelerating bacterial translocation. HIV infection is currently recognized for its ability to create dysbiosis ${ }^{17}$ and destabilization of physiological viral communities associated with the human intestine ${ }^{18}$, while the progression of the disease increases the total amount of viruses discharged into plasma ${ }^{19}$. Microbial products, as well as other substances that are locally generated during the translocation and inflammation of the mucosa, pass into the portal blood stream, being transported to the liver, where hepatocytes, hepatic stellate cells and Kupffer cells will activate additional proinflammatory and profibrotic pathways. The ability of the virus to reduce the number of Kupffer cells while concomitantly affecting the liver function by unknown mechanisms ${ }^{20}$ is specific for the HIV infection.

\section{Esophageal damage in HIV-infected patients}

HIV-infected patients are at greater risk to develop esophagitis, especially those who don't receive HAART. Most patients at risk are those with CD4+ counts lower than 100 cells $/ \mu \mathrm{L}$. In the general population, the main cause of esophagitis is represented by gastroesophageal reflux disease (GERD) ${ }^{21}$, while in HIV patients the etiology of esophagitis is predominantly infectious, the etiological agents being viruses, fungi, bacteria or even parasites.

The differential diagnosis of ulcers and ulcerations in the context of extended esophagitis should be made between infectious esophagitis (HIV, Candida spp., CMV, HSV, etc.) and other causes characteristic for pathological entities that can coexist with HIV infection - eosinophilic esophagitis, Crohn's disease, tuberculosis, etc. The endoscopic features may be helpful for the diagnostic process, but are not sufficient (Table 3). 
Table 2. Etiology of esophageal lesions in HIV-infected patients ${ }^{22,23}$.

\begin{tabular}{cc}
\hline & Common cases \\
\hline Fungi & Candida \\
\hline Viruses & CMV, Herpes simplex type I \\
\hline Idiopathic & Idiopathic esophageal ulcer \\
\hline Medication & Uncommon causes \\
\hline Peptic & Zalcitabine, zidovudine \\
\hline & GERD \\
\hline Viruses & Rare causes \\
\hline Fungi & Epstein-Barr, Papovavirus, HHV-6, adenovirus ${ }^{22}$ \\
\hline Bacteria & Mycobacterium avium, Mycobacterium tuberculosis, Rochalimae henselae, Nocardia asteroids, \\
Prtinomyces israelii complex
\end{tabular}

Table 3. The differential diagnosis of infectious esophagitis in HIV-infected patients ${ }^{24}$.

\begin{tabular}{cccccc}
\hline & Topography & Number of lesions & Size & Shape & Depth \\
\hline HIV & middle $1 / 3$ & $\begin{array}{c}\text { Single (giant/ } \\
\text { solitary ulcer) } \\
\text { multiple }\end{array}$ & $\begin{array}{c}\text { Gigantic } \\
(5-10 \mathrm{~cm})\end{array}$ & Oval & Deep \\
\hline CMV & $\begin{array}{c}\text { distal } 1 / 3+/- \text { es- } \\
\text { ogastric junction }\end{array}$ & Multiple & $\begin{array}{c}\text { Gigantic } \\
(3-5 \mathrm{~cm})+/ \text { small- } \\
\text { er lesions }\end{array}$ & Oval & Superficial \\
\hline HSV & proximal $1 / 3$ & Multiple & Small & Oval or round & Superficial \\
\hline Candida albicans & $\begin{array}{c}\text { proximal and mid- } \\
\text { dle } 1 / 3\end{array}$ & Multiple & Small & $\begin{array}{c}\text { Linear, longitudi- } \\
\text { nally disposed }\end{array}$ & Superficial \\
\hline
\end{tabular}

Esophageal neoplasia in HIV-infected patients. Lymphomas and Kaposi's sarcoma are the most common esophageal neoplasia in HIV-infected patients ${ }^{25}$. Kaposi's sarcoma is the most common malignant tumor associated with AIDS (approx. $40 \%$ of patients) and, in most cases, it is asymptomatic.

Gastroesophageal reflux disease (GERD) in HIV-infected patients. Data on the prevalence rate of GERD in these patients are contradictory, some studies reporting a prevalence greater than $50 \%$ of the cases, with more than a half symptomatic ${ }^{26}$, while other studies claim that the prevalence rate of GERD in HIV-infected patients is relatively low compared to general population ${ }^{25}$.

Gastric and duodenal damage in HIV-infected patients. HIV infection is associated with marked chronic inflammation of the gastric mucosa, a decrease in acid secretion and increased gastric $\mathrm{pH}$ during fasting ${ }^{27,28}$. Extensive studies were performed on the evolution of the $H$. pylori infection associated with HIV infection. It has been observed that HIV infection is associated with a higher frequency of extensive distribution of inflammation, pangastritis type, associated with hypochloraemia and increases in serum gastrin concentrations. Moreover, in $H$. pylori-HIV coinfection, hypochloraemia is not caused by gastric atrophy, but by the extended inflammation of the gastric mucosa, and the HIV infection in the absence of $H$. pylori infection does not cause the alkalinization of gastric content, while the HIV-H. pylori coinfection determines the highest $\mathrm{pH}$ values, demonstrating an additive effect of the association ${ }^{29}$.

A review published in 2014 that looked at the incidence of $H$. pylori infection in HIV patients reported higher rates of $H$. pylori infection in patients not infected with HIV and an inverse correlation between the immunosuppression degree, reflected by the number of peripheral CD4+ cells and the prevalence of the active infection with $H$. pylori, leading to the conclusion that $H$. pylori needs a functional immunological status ${ }^{30}$ for a persistent colonization.

In HIV-infected patients, the etiology of peptic ulcers is not linked to the presence of $H$. pylori at the gastric level. Ulcers occur on the background of the chronic inflammation of gastric mucosa, the etiology being more commonly linked to the presence of 
opportunistic infections, especially CMV infection. Therefore, biopsy sample harvesting is recommended in order to exclude those type of infections which are more probable when the lymphocyte depletion is more pronounced - $\mathrm{CD} 4+$ values lower than $200 / \mu L^{31}$

\section{Conclusions}

Upper digestive endoscopy is a helpful investigation for HIV-infected patients and should be performed in all symptomatic patients and all patients with low CD4+ cell counts, irrespective of the presence or the absence of suggestive digestive symptomatology, because the latter presents a relative risk $R R=2.16$ with statistical significance $(p=0.004$, CI $95 \%$ ) of presenting lesions of the upper digestive segments.

The most frequently affected segment is the esophagus. The patients with a low CD4+ cell counts present a relative risk $\mathrm{RR}=1.77$, which is statistically significant ( $\mathrm{p}=0.02$, CI 95\%), of presenting esophageal lesions compared to the control group (normal CD4+ cell counts). The relative risk for esophagitis in patients with low CD4+ cell counts is $\mathrm{RR}=1.38$, which is statistically insignificant $(\mathrm{p}=0.28, \mathrm{CI} 95 \%)$. Esophageal ulcers are frequently found in patients with low CD4+ cell counts (20.58\%), their presence at endoscopic examination being representative for lymphocyte depletion.

Gastric lesions are rarer than esophageal lesions in HIV-infected patients, the most common lesion being the extensive inflammation of the gastric mucosa (pangastritis). Although the relative risk of gastric and/or duodenal lesions is greater in patients with lymphocyte depletion, $\mathrm{RR}=2.54$, the result has no statistical significance ( $\mathrm{p}=0.97$, CI 95\%). The most common gastric lesion is gastritis, which in patients with lymphocytic depletion affects the entire gastric mucosa (pangastritis is 7 times more common than antral gastritis), while in patients with normal CD4+ cell counts we noticed equal proportions for antral gastritis and pangastritis. HIV-infected patients with lymphocyte depletion present a higher risk of gastritis than those with normal CD4+ cell counts $(\mathrm{RR}=0.75$, $p=0.44$, CI 95\%). The relative risk of gastric or duodenal ulcer is slightly higher in patients with normal $\mathrm{CD} 4+$ cell counts, but has no statistical significance $(\mathrm{RR}=1,25, \mathrm{p}=0,78$, CI 95\%).

The lymphocyte depletion is not linked to a higher risk of chronic viral hepatitis $(\mathrm{RR}=0.43$, CI $95 \%, p=0.057)$ nor to a higher risk of portal hypertension in patients with concomitant infection (HIV and hepatitis viruses), $R R=0.88$, CI $95 \%, p=0.88$, but the results obtained are not significant from a statistical point of view.

The identification of esophageal or gastric lesions requires biopsy sampling for a diagnosis of certainty, the main pathologies discovered endoscopically in HIV-infected patients having a different etiology than the lesions identified in immunocompetent patients.

The lymphocyte depletion (decrease of CD4+cell number) is a risk factor for the development of pathological changes in the upper segments of the digestive system, most frequently affecting the esophagus under the form of esophagitis. We also noticed a higher frequency of gastric or duodenal ulcers in these patients.

The high proportion of endoscopic abnormalities recommends the use of upper digestive endoscopy as a screening method for all HIV-infected patients with low CD4+ cell counts, regardless of the presence or absence of digestive symptoms.

\section{Declarations}

„All the patients signed an informed consent. The study was approved by the Ethics Committee of the National Institute for Infectious Diseases „Prof. Dr. Matei Bals", Bucharest, Romania"

"All the patients included in the study signed the consent for publication"

\section{Availability of data and material: yes}

"The authors declare that they have no competing interests"

„This research received no specific grant from any funding agency in the public, commercial, or non-for-profit sectors"

\section{Acknowledgements \\ None}

\section{References}

1. AIDS info, Guidelines for the Prevention and treatment of opportunistic infections in HIV-infected adults and adolescents. https://aidsinfo.nih.gov/guidelines/html/4/ adult-and-adolescent-oi-prevention-and-treatment-guidelines/354/primary-prophylaxis. (2017, accessed 10 June, 2019).

2. Anton PA, Elliott J, Poles MA, et al. Enhanced levels of functional HIV-1 co-receptors on human mucosal T cells demonstrated using intestinal biopsy tissue. AIDS 2000; 14(12):1761-1765.

3. Arora M, Goldberg EM. Kaposi Sarcoma involving the gastrointestinal tract. Gastroenterol Hepatol (N.Y.) 2010;6(7):459-462. 
4. Attwood SE, Lamb CA. Eosinophilic oesophagitis and other non-reflux inflammatory conditions of the oesophagus: diagnostic, imaging and management. Best Pract Res Clin Gastroenterol 2008;22(4):639-660.

5. Bach MC, Howell DA, Valenti AI, et al. Aphthous ulceration of the gastrointestinal tract in patients with the acquired immunodeficiency syndrome (AIDS). Ann Intern Med 1990;112:465-467.

6. Bader M, Yi Y. Gastroesophageal reflux disease in HIV-infected adults: prevalence and risk factors of moderate-severe or frequent symptoms. Open Forum Infectious Disease 2016;3(Suppl_1):1529.

7. Socea B, Smaranda AC, Nica AA, et al. Postcolonoscopy acute appendicitis - our case series and review of literature. Arch Balk Med Union 2018;53(4):599-602.

8. Socea B, Smaranda A, Nica AA, et al. Spiegel hernia - case presentation. Arch Balk Med Union 2018;53(1):152-154.

9. Diaconescu D, Pantea Stoian A, Socea L, et al. Hepato-renal syndrome: a review. Arch Balk Med Union 2018;53(2):239-245.

10. Balagopal A, Ray SC, De Oca RM, et al. Kupffer cells are depleted with HIV immunodeficiency and partially recovered with antiretroviral immune reconstitution. AIDS 2009;23(18):2397-2404.

11. Bhaijee F, Subramony C, Tang S-J, et al. Human immunodeficiency virus-associated gastrointestinal disease: common endoscopic biopsy diagnoses. Patholog Res Int 2011;2011:247923.

12. Blitman NM, Muhamad A. Idiopathic giant esophageal ulcer in an HIV-positive child. Pediatric Radiology 2002;32(12):907-909.

13. Diaconu C, Balaceanu A, Morosan E. Sepsis biomarkers: past, present and future. Farmacia 2015;63(6):811-815.

14. Bonacini M, Young T, Laine I. The causes of esophageal symptoms in human immunodeficiency virus infection: a prospective study of 110 patients. Arch Intern Med 1991;151:1567-1572.

15. Ginghina O, Negrei C, Hudita A, et al. In vitro impact of some natural compounds on HT-29 colorectal adenocarcinoma cells. Farmacia 2017;65(6):947-953.

16. Boulware DR, Hullsiek KH, Puronen CE, et al. Higher levels of CRP, D-dimer, IL-6, and hyaluronic acid before initiation of antiretroviral therapy (ART) are associated with increased risk of AIDS or death. J Infect Dis 2011;203(11):1637-1646.

17. Boumans D, Kootstra G-J, van Olffen GH, et al. Adenovirus esophagitis in an HIV-positive patient - extraordinary presentation of a common viral infection - case report. Infectious Diseases in Clinical Practice 2012;20(5):354-356.
18. Brenchley JM, Paiardini M, Knox KS, et al. Differential Th17 CD4+ T-cell depletion in pathogenic and nonpathogenic lentiviral infections. Blood 2008;112(7):2826-2835.

19. Brenchley JM, Price DA, Schacker TW, et al. Microbial translocation is a cause of systemic immune activation in chronic HIV infection. Nat Med 2006;12(12):1365-1371.

20. Brenchley JM, Schacker TW, Ruff LE. CD4+ T cell depletion during all stages of HIV disease occurs predominantly in the gastrointestinal tract. J Exp Med 2004;200(6):749-759.

21. Canalejo Castrillero E, Garcia Duran F, Cabello N, et al. Herpes esophagitis in healthy adults and adolescents: report of 3 cases and review of the literature. Medicine (Baltimore) 2010;89:204-210

22. Chang Y, Cesarman E, Pessin MS. Identification of herpes virus-like DNA sequences in AIDS-associated Kaposi's sarcoma. Science 1994;266(5192):1865-1859.

23. Chiu HM, Wu MS, Hung CC. Low prevalence of Helicobacter pylori but high prevalence of cytomegalovirus-associated peptic ulcer disease in AIDS patients: comparative study of symptomatic subjects evaluated by endoscopy and CD4+ cell counts. J Gastroenterol 2004;19:423-428.

24. Egger M, May M, Chene G, et al. Prognosis of HIV1-infected patients starting highly active antiretroviral therapy: a collaborative analysis of prospective studies. Lancet 2002;360(9327):119-129.

25. Epstein DP, Locketz M. Oesophageal ulceration in HIV-infected patients. S Afr Med J 2009;99(2):107-109.

26. Ho M. Epidemiology of virologic and pathogenetic aspects of cytomegalovirus infections. Rev Infect Dis 1990;12: S701-710.

27. Hoshino K, Shibata D, Miyagi T. Cytomegalovirus-associated gastric ulcers in a patient with dermatomyositis treated with steroid and cyclophosphamide pulse therapy. Endoscopy 2011;43:E277-278.

28. Kakugawa Y, Kami M, Matsuda T. Endoscopic diagnosis of cytomegalovirus gastritis after allogenic hematopoietic stem cell transplantation. World J Gastroenterol 2010;16:2907-2912.

29. Kaplan JE, Masur H, Holmes KK, et al. Guidelines for preventing opportunistic infections among HIV-infected persons, CDC - Center for Disease Control and Prevention, MMWR, 2002, https://www.cdc.gov/mmwr/preview/ mmwrhtml/rr5108a1.htm. (accessed 10 June, 2019).

30. Knox TA, Spiegelman D, Skinner SC, et al. Diarrhea and abnormalities of gastrointestinal function in a cohort of men and women with HIV infection. American Journal of Gastroenterology 2000;95(12):3482-3489.

31. Kuipers EJ, Thijs JC, Festen HP. The prevalence of Helicobacter pylori in peptic ulcer disease. Aliment Pharmacol Ther 1995;9(Suppl. 2):59-69. 